\title{
Tensions and coalitions: A new trade agreement affects the policy space for nutrition in Vietnam
}

\author{
Jody Harris ${ }^{1}\left(\mathbb{0} \cdot\right.$ Tabitha Hrynick $^{1} \cdot$ Mai Thi My Thien ${ }^{2,3} \cdot$ Tuyen Huynh $^{4} \cdot$ Phuong Huynh $^{5} \cdot$ Phuong Nguyen $^{6}$. \\ Anne-Marie Thow ${ }^{7}$
}

Received: 27 May 2021 / Accepted: 29 January 2022 / Published online: 2 March 2022

(C) The Author(s) 2022

\begin{abstract}
Global trade has shaped food systems over centuries, but modern trade agreements are hastening these changes and making them more complex, with implications for public health and nutrition transition. This study aimed to understand the impact of the 2018 Comprehensive and Progressive Agreement for Trans-Pacific Partnership (CPTPP) on the policy space for public health nutrition in Vietnam. We conducted comparative document review and key informant interviews, and our analysis drew on a framework of policy space and the theory of advocacy coalitions. We identified 10 CPTPP sections with potential public health nutrition implications; and 50 Vietnamese policies relevant to nutrition having one or more tensions with one or more CPTPP sections. A majority of policy tensions were in sections of the CPTPP relating to technical barriers to trade and government procurement; most tensions related to protecting policy-making from vested interests. Different groups of policy actors hold different beliefs and interests on these issues, and therefore promote different framings and policy approaches. We identified two advocacy coalitions working very separately on issues affecting nutrition policy space: a trade coalition holding the policy position that free trade improves nutrition by default; and a nutrition coalition holding the policy position that nutrition should be explicitly considered in trade policy. The policy space for nutrition in Vietnam has important potential constraints through written policy, and the trade and nutrition coalitions will need to interact more regularly and constructively in order to foresee where these tensions will arise in practice, and create plans for their mitigation. This study adds to global evidence of free trade agreement impacts on nutrition policy space, and we extend previous work by explaining these actor groupings in the policy space through the theory of advocacy coalitions.
\end{abstract}

Keywords Trade $\cdot$ Nutrition $\cdot$ Policy space $\cdot$ Advocacy coalitions $\cdot$ Vietnam

This article belongs to the Topical Collection on Stories of Change in Nutrition: Lesson from Africa and Asia

Guest Editors: Stuart Gillespie, Nicholas Nisbett, Mara van de Bold, Jody Harris

Jody Harris

j.harris@ids.ac.uk

Institute of Development Studies (IDS), Brighton, UK

2 Queensland University of Technology, Brisbane, Australia

3 Ho Chi Minh Centre for Disease Control, Ho Chi Minh City, Vietnam

4 International Center for Tropical Agriculture (CIAT), Hanoi, Vietnam

5 National Institute of Nutrition, Hanoi, Vietnam

6 International Food Policy Research Institute (IFPRI), Hanoi, Vietnam

7 University of Sydney, Sydney, Australia

\section{Introduction}

Global trade has shaped food systems over centuries, but modern trade agreements are hastening these changes and making them more complex. At their most basic, these agreements - bilateral or multi-country treaties to facilitate trade between signatories - influence what foods are traded and where, thus shaping which foods are available in domestic markets and at what price. On average, $17 \%$ of food worldwide goes through cross-border trade, though these numbers rise for some countries (Singapore imports $90 \%$ of its food) and for some foods (staple foods, sugars and oils are among the most traded, but trade in fruits, vegetables and meat is also rising) (Global Panel on Agriculture \& Food Systems for Nutrition, 2020). One objective of trade between countries therefore is to balance supply and demand in different locations, leveraging comparative advantage and 
meeting need, and making available a broader range of foods in a longer list of places (Global Panel on Agriculture \& Food Systems for Nutrition, 2020).

Modern trade agreements go further than this in shaping different spheres of policy in signatory countries however, and may additionally affect the space that national governments have to create or enforce policy that protects other public welfare outcomes, such as health and nutrition (Thow et al., 2015, 2018). The process of trade negotiation normally focuses on economic growth outcomes for exporting nations, and food security and food safety outcomes for importers, with little attention to public health nutrition at either end; several recent high-profile articles have highlighted the need to protect policy space for these welfare outcomes (Friel et al., 2020; Popkin et al., 2020; Swinburn et al., 2019).

There is therefore a need to understand - in detail and in context - the implications of trade agreements for nutrition and health, and how they shape both the food environment and the 'enabling environment' for public health nutrition policy more broadly. This study aimed to understand the potential impact of a new multi-country trade agreement on the policy space for public health nutrition in Vietnam, and the positions of public policy actors in sectors related to these issues.

\subsection{Characteristics of the issues: Trade and nutrition}

The 'nutrition transition' from traditional to modern diets is now a global phenomenon (Popkin, 2017), with many countries in the world struggling with significant burdens of both undernutrition and overweight-related chronic disease as a consequence (Development Initiatives, 2020a; Popkin et al., 2020). A contributor to this dietary change has been changing food environments (Turner et al., 2018). Modern food environments have both positive and negative implications for diets, with more fresh and nutrient-rich foods available to those who can afford and access them; but more ultraprocessed and nutrient-poor foods available too, and often at lower prices per calorie (Global Panel on Agriculture \& Food Systems for Nutrition, 2016; Hirvonen et al., 2019). There is growing consensus among food systems and public health researchers that global trade structures for food are a key driver of nutrition and health changes (Werner et al., 2019), and are a 'missed opportunity' for policy engagement that could be part of the solution to the more detrimental aspects of the nutrition transition (Global Panel on Agriculture \& Food Systems for Nutrition, 2020).

Conceptual work has highlighted how trade liberalisation can impact nutrition through facilitating trade in goods, and subsequent effects on production and prices; facilitating investment and trade in services, and subsequent effects on competition and marketing; and initiating changes in protection for domestic industry, and subsequent changes in national specialisations and commodity dumping (Thow, 2009). These processes have different effects on the availability, affordability, accessibility and safety of different foods depending on context, and play out alongside economic and livelihood effects of trade policy that also affect food consumption. Empirical work has identified both positive and negative implications for nutrition and public health from modern trade agreements:

Beyond making a broader range of foods available, a positive outcome is that stricter trade standards have in general improved food safety standards in the formal sector of low- and middle-income countries (Jaffee et al., 2018). In addition, most trade agreements at least pay lip-service to population welfare, containing clauses that protect policy space for key social goods such as health (for example the World Trade Organisation's General Agreement on Tariffs and Trade 'general exception'), even if these often fail to protect welfare in practice (Friel et al., 2020). Less positively, implementation of trade agreements is consistently associated with increased consumption of highly processed foods and sugar-sweetened beverages, key drivers of the nutrition transition, as well as with higher overweight/obesity and cardiovascular disease incidence, though quantitative evidence remains relatively weak (Barlow et al., 2017).

In terms of political processes, trade and investment agreements are found to reduce the autonomy of governments in food system policy making. In particular, investor protections and rules around non-discrimination and crossborder services, alongside reduced revenues after decreased tariffs, reduce the ability of governments (particularly economically or politically weaker governments) to intervene through national policy or public health programmes to shape consumption of healthy or less-healthy foods (Thow et al., 2015). For instance, rules around technical barriers to trade and intellectual property reduce the ability of governments to regulate food labelling and advertising (Greenberg $\&$ Shiau, 2014; Thow et al., 2015); and rules around government procurement open food tenders in institutions such as schools and hospitals to a broader range of companies, and limit government's ability to select providers based on public health concerns (Greenberg \& Shiau, 2014).

The most challenging aspects of trade agreements for public health nutrition policy are the ways in which they can 'lock in' power differentials, which are most evident for weaker countries and weaker institutions (including public health) within countries. Requirements framed as transparency and regulatory coherence, for instance, encourage the participation of private sector stakeholders in setting regulatory processes, increasing the potential for conflicts of interest and limiting the ability of governments to prioritise public health interests (Greenberg \& Shiau, 2014; Thow et al., 2015). And rules on investments and legally-mandated 
Investor-State Dispute Settlement (ISDS) mechanisms allow corporations to sue governments over domestic laws, potentially including public health laws, if they impact significantly on investors and trade (Mitchell \& Sheargold, 2015).

\section{The Vietnamese trade and nutrition context}

\subsection{Political and economic context}

The current study investigates each of these issues in the context of contemporary Vietnam. Vietnam has seen rapid social and economic change within a generation, transforming from one of the world's poorest countries at the end of a succession of wars in 1975, to the country with the highest human capital index among all middle-income countries today. ${ }^{1}$ Since economic reforms in 1986, poverty rates have fallen significantly in Vietnam, though with the speed of these changes there are now significant disparities between rural and urban populations and between the ethnic majority and the many minority groups in the country (Harris et al., 2021). Bureaucracy also has been unable to keep pace with rapid economic change, leading to low capacity for policy engagement and enforcement and minimal institutional mechanisms for accountability to welfare policy such as for nutrition (Harris et al., 2016). Civil society in the country is limited in scope and influence to address these issues also (Wells-Dang, 2014). Overall, Vietnam's social and political history has created a country that is increasingly aligned to global markets, but that has a stronger focus on social policy (particularly education and health) than many other countries in similar economic brackets (Baulch, 2016).

International trade accounts for $17.8 \%$ of Vietnamese GDP, with food and agriculture accounting for $17 \%$ of export value and agriculture and aquatic products accounting for $8.7 \%$ of import turnover, ${ }^{2}$ and Vietnam is increasing imports of processed food and frozen meat in particular (Raneri et al., 2019). The government is committed to growing international trade, and Vietnam has 16 free trade agreements either already launched or in negotiation (4 bilateral signed, 3 bilateral in negotiation, 7 signed through membership of the Association of Southeast Asian Nations (ASEAN), 1 large multi-country agreement in negotiation, and one large multi-country agreement - the Comprehensive and Progressive Agreement for Trans-Pacific Partnership (CPTPP) - recently ratified). ${ }^{3}$ Vietnam has been party

\footnotetext{
${ }_{1}$ https://www.worldbank.org/en/country/vietnam/overview

2 http://en.aecvcci.vn/tin-tuc-n4701/vietnam-importexport-report2018.htm

3 https://aric.adb.org/fta-country
}

to negotiations over the CPTPP since 2010: Formerly the Trans-Pacific Partnership (TPP), re-named after the withdrawal of the United States in 2017 as the CPTPP, this is the third largest free trade area in the world by Gross Domestic Product (GDP), bringing together eleven countries around the Pacific. The National Assembly of Vietnam ratified the CPTPP in November 2018, and it entered into force in January 2019.

\subsection{Nutrition and health context}

Through these social and economic changes, Vietnam is at the start of a nutrition transition, with undernutrition falling substantially in most populations in the country, but overweight and non-communicable diseases (NCDs) rising, particularly in urban areas (Harris et al., 2020). Child stunting is declining in Vietnam, currently sitting at $24 \%$ nationally, though still at $40 \%$ in the poorest ethnic minority groups (Harris et al., 2021). At the same time, $12 \%$ of adolescent boys and $8 \%$ of adolescent girls are overweight nationally, and this rises to $30 \%$ among children in some urban areas (Development Initiatives, 2020a, b; Mai et al., 2020). Among adults, $21 \%$ of women and $16 \%$ of men are overweight, and $5 \%$ of adults are currently living with diabetes and $24 \%$ with high blood pressure (Development Initiatives, 2020b).

Food system drivers of this transition show that national availability of sugars, sweetened beverages, oils and fats has risen in recent years, and consumption of sugars and fats has increased (Harris et al., 2020). Expenditure share on food eaten away from home, in many contexts a marker for less healthful diets, has increased over time in all groups, though expenditure shares are larger in urban and richer populations (Harris et al., 2020). Overall, Vietnam can currently be assessed as a 'Stage 2' country in the nutrition transition scale (Paarlberg, 2012), with rapidly falling poverty, generally adequate public services, and increasing private sector investment. However, there are still pockets of the country, in particular ethnic minority communities, who are stuck in Stage 1 and lack even basic services and livelihood security; and Vietnam's major cities more closely resemble Stage 3, with high levels of private sector engagement in food yet little regulation.

Nutrition policy formulation in Vietnam falls under the health sector, and is in general seen as comprehensive, with revisions over time keeping pace with changing nutrition profiles in the country: from hunger, to undernutrition, to nutrition transition (Mbuya et al., 2019). Recent assessment has found that for non-communicable disease policy, Vietnam's policy is salient and comprehensive, but that issues such as equity, gender and rights need further attention (Buse et al., 2020). 


\section{Objectives and approach}

This study was inspired by the ratification of the CPTPP in 2018 to look at Vietnam's emerging nutrition transition through the lens of its newest trade policy. The ratification allowed us to research a recent trade policy process in a rapidly changing nutritional context, which is why we opted to work on this topic in Vietnam. We ask whether the CPTPP has potential or actual impacts on nutrition policy space, and how these are seen by different actors in the policy-making process. The objectives of this case-study are to analyse the impacts of the newly-ratified CPTPP on policy space for public health nutrition in Vietnam; to investigate policy actor engagement and understanding of these impacts; and to elaborate implications for policy processes in Vietnam and elsewhere.

This study is part of a larger project called Stories of Change in Nutrition (SOC) ${ }^{4}$ which uses a multi-method and comparative country case study approach to understand the drivers of changes and challenges associated with tackling obesity and non-communicable disease within a context of broader forms of malnutrition. The objectives of SOC are to investigate what drives political attention and policy traction to the challenge posed by the nutrition transition; and foster learning across contexts on approaches for turning obesogenic into enabling environments for better nutrition, and developing effective policy and programmatic responses.

The study received ethical approval from the International Food Policy Research Institute IRB board (as the home of the SOC project), and the National Institute of Nutrition review board in Vietnam. Informed consent procedures were followed with interview respondents, including explanation of the study aims and approaches, and the right to withdraw from the research without penalty at any time.

\subsection{Conceptual framework}

This research analyses 'policy space': the agency and available tools and mechanisms that policy actors have in creating, reforming or implementing policy towards their own goals (Crichton, 2008; Grindle \& Thomas, 1991). Policy space can expand or contract depending on changes in national and international contextual factors; the policy process itself, including sets of actors and their agendas; and how acceptable policy content is to different policy actors and their support or opposition to it. Assessments of policy space have previously been applied to nutrition

\footnotetext{
${ }^{4}$ https://www.ifpri.org/project/stories-change-nutrition
}

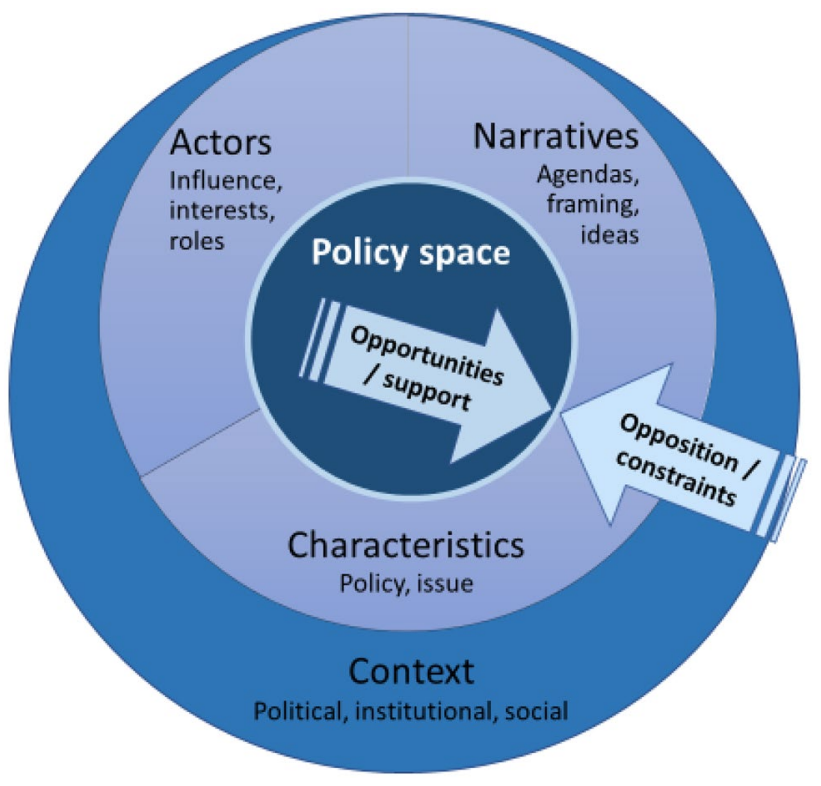

Fig. 1 Conceptual framework of policy space in this work. Source: Author adaptation of the Policy Space framework (Grindle \& Thomas, 1991) incorporating broader policy process theories (Keeley \& Scoones, 1999; Shiffman, 2007)

(Thow et al., 2016), including for issues of global trade (Thow et al., 2015).

In this study, we explicitly extended a recognised model of policy space (Grindle \& Thomas, 1991) with reference to key conceptual frameworks from the fields of global health agenda setting (Shiffman, 2007), and critical political economy (Keeley \& Scoones, 1999), in order to more completely conceptualise interplays of structure and agency in policy making. Between them, these frameworks focus on actors and their relative power and interests; narratives, ideas and the framing of issues and solutions; the characteristics of both the issue and its related policy in different sectors; and the policy context in terms of the broader social, institutional and political situation within which the policy process takes place. We combined these ideas into a single framework, illustrated in Fig. 1.

We summarised the Vietnamese context and the characteristics of the trade and nutrition issue in previous sections; and we summarise the roles of different actors and their narratives on these issues in the sections below. We then look across these factors in order to understand the opportunities to expand policy space for public health nutrition, and the constraints that might contract this space, in the context of the CPTPP trade policy in Vietnam. This combined theoretical framework was drawn upon in order to frame the research, create interview guides, and guide the initial analysis (coding) and extended analysis (application of theory). 
Table 1 Interview respondents by sector and organisation type

\begin{tabular}{llll}
\hline Sector & Interviews & Organisation type & Interviews \\
\hline Cross-sector & 3 & Government & 7 \\
Development & 1 & Private sector and lobbyists & 4 \\
Food and agriculture & 1 & NGO & 1 \\
Nutrition and health & 4 & Academia/Research & 2 \\
Trade and business & 5 & & \\
Total & $\mathbf{1 4}$ & Total & $\mathbf{1 4}$ \\
\hline
\end{tabular}

\subsection{Data sources and sampling}

This qualitative case-study drew on two major sources of data: 1) A review and comparative analysis of 50 written policies relating to nutrition in Vietnam; and 2) keyinformant interviews $(n=14)$ with actors across trade, agriculture and nutrition, and across different organisation types (Table 1).

The policy document review aimed to identify synergies and tensions between the CPTPP text and nutrition-relevant policies. These policy documents were sourced from the health sector, where nutrition policy is made in Vietnam; and from other relevant sectors, most notably food and agriculture and poverty reduction, where these were salient to nutrition issues. In total, 83 national policies in the areas of nutrition and health, food, and economic development that would have relevance to public health nutrition were identified (from a previous review in a related project (Harris et al., 2021)) after excluding duplicated or expired policies. Of the policies reviewed, 33 did not have identifiable food or nutrition interactions with the CPTPP, particularly policies related specifically to poverty reduction, leaving 50 policies to be included in this study.

The key-informant interviews aimed to gauge understanding of potential policy implications affecting policy space, and the engagement of different actors in the Vietnamese trade policy process. In order to understand a range of views on the topic of trade and nutrition policy, key informants were purposively sampled largely from the nutrition and health, and trade and business sectors; additional insight was sought from those working more broadly in development or agriculture, or across different sectors. Given the range of actors involved in trade policy and nutrition policy making, key informants were sought largely from the government and private sector, but also from non-government organisations (NGOs, United Nations-UN) and academic institutions involved in these issues. Not all key informants had been directly involved in the CPTPP process, as we wanted to understand sectors (such as nutrition) which may not have been invited to trade talks but who would have views on the topic of the research. We aimed for data saturation, curtailing the number of interviews when similar information was being gained from additional respondents.

\subsection{Document review}

For the document review, first each of the 30 sections of the final version of the CPTPP were reviewed by one author ( $\mathrm{THr}$ ) under the guidance of other authors (AMT and JH) to identify text that was potentially of concern with relation to public health nutrition policy space in a context of the nutrition transition, and text that was potentially protective of nutrition policy space. This review of the CPTPP was based on what is already known about interactions between trade and nutrition policy (reviewed in the introduction above, and drawing in particular on the framework elaborated in Thow, 2009). Ten sections of the CPTPP were found to have potential interactions with public health nutrition issues through this framework, according to the narrative review undertaken.

Next, the 50 included policies were read in Vietnamese language by one author (MT), and their content crossreferenced with the 10 CPTPP sections found to have potential interactions through the review above. Each potential interaction between national policy and the CPTPP text (based on the framework of Thow, 2009) was recorded narratively in a matrix, and discussed among the authors. Subsequently, each interaction was coded by the lead author $(\mathrm{JH})$ according to its area of potential impact, based on the World Health Organisation (WHO) NCD Global Action Plan ${ }^{5}$ (these are: protecting policymaking from vested interests; specific policy options to reduce less healthy food options, or increase healthy food options; and policies to support institutional action and consumer education), extended with issues that came up in the interviews that were not covered by the guidelines (food safety, and economic and export provisions).

See Annex 1 for the full table of cross-references between policies (based on Thow, 2009 and the broader literature review above) and their categorization (based on the WHO NCD action plan). Numbers of policies interacting with

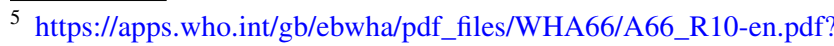
ua $=1$
} 
the different CPTPP sections, and numbers of interactions mapped to the different areas of the NCD action plan, were summarised in charts.

\subsection{Key informant interviews}

The semi-structured interview guide was developed based on the study frameworks, and asked about the background and organisational priorities of respondents; respondent understanding of the drivers of both trade and nutrition issues and policy responsibility for these; any interactions between trade and nutrition actors; the process of the CPTPP trade negotiation policy (where actors were directly involved); and opinions on need, barriers or opportunities to address nutrition through trade policy. The interview guide was translated into Vietnamese and discussed among bi-lingual study authors (MT and PHN) to check for consistency of meaning, then piloted in Vietnamese with colleagues at the National Institute of Nutrition and revisions made to unclear questions.

The interviews were undertaken by one author (MT) in Vietnamese or English (depending on the language most comfortable to the respondent) and transcribed verbatim, then all Vietnamese interview transcripts were translated into English. The interviewees are identified in this paper by their number and sector (e.g. 08_tr as interviewee number 8 from the trade or business sector, _ag as agriculture, and _nu as nutrition). Transcripts were organised in NVivo 12 qualitative analysis software for initial coding by one author (THr).

First, each interview was read individually, and an interview summary created which described the respondent in terms of role and position; key themes of the interview in terms of nutrition and trade; any information provided on the CPTPP policy process; and a narrative summary of the interview including the respondent's positionality on the issues, and the researcher's analytical notes. Initial descriptive coding was inductive, creating codes directly from the texts being analysed. A total of 94 codes were categorised broadly into respondent priorities; general thoughts on nutrition and trade; involvement in trade policy processes; barriers and facilitators to public health nutrition; notes on Vietnamese policy more generally; and additional codes on adjacent topics such as media and food safety. These initial codes were reviewed by co-authors (JH and AMT), and a next level of analytical codes created around themes from the conceptual framework (issue characteristics; actor power and interests; ideas, narratives and framing; policy characteristics and processes; and the political, institutional and social context). Analytical notes were created from these, drawing out findings as patterns or discords in the data within each theme, among different types of respondents.

\subsection{Synthesis}

The policy review and interview findings were then read together, to describe the potential impacts of the CPTPP on Vietnam's public health nutrition policy space, and to analyse the perceptions of different policy actors and implications for public health nutrition in Vietnam. The lead author $(\mathrm{JH})$ used the analytical interview notes and document review synthesis in a final level of analysis, referencing concepts from the framework to draw out key findings. A concurrent reading of social and political theory suggested that the idea of different advocacy coalitions (Sabatier \& Weible, 2007) working in the policy space along with their different interests, beliefs and policy positions could help explain the emerging empirical findings and generalise them to other contexts. We reflect on the methodological implications of our analytical process in the discussion section below.

\section{Findings}

\subsection{Tensions in written policy}

\subsubsection{Main international guidelines and Vietnamese policy provisions}

The World Health Organisation has published a list of 'bestbuy' interventions aimed at heading off nutritional disorders seen to be rising as countries undergo nutrition transition. ${ }^{6}$ These include reductions in salt, sugar and trans-fat intake; promotion of breastfeeding and healthy diets; and improved nutrition literacy among populations. These are to be achieved through policy interventions to protect and promote healthy food options; reduce availability and access to less healthy food options; support institutional action and consumer education; and protect policy space from vested interests (Thow et al., 2016).

The Government of Vietnam has clearly stated policy priorities to improve nutrition, including population diet and micronutrient status, maternal and child undernutrition, and prevention of obesity and diet-related NCDs (Decision 226 /QĐ-TTg: Ratification of the National Nutrition Strategy $(N N S)$ for $2011-2020^{7}$ ). Key policy priorities include the development of advertising restrictions and tax policy to disincentivise unhealthy food production and consumption; the creation of full legislation to bring coherence to prevention and control activities; the

\footnotetext{
${ }^{6}$ https://www.who.int/ncds/management/WHO_Appendix_BestBuys. pdf

${ }^{7}$ https://extranet.who.int/nutrition/gina/en/node/11519
} 


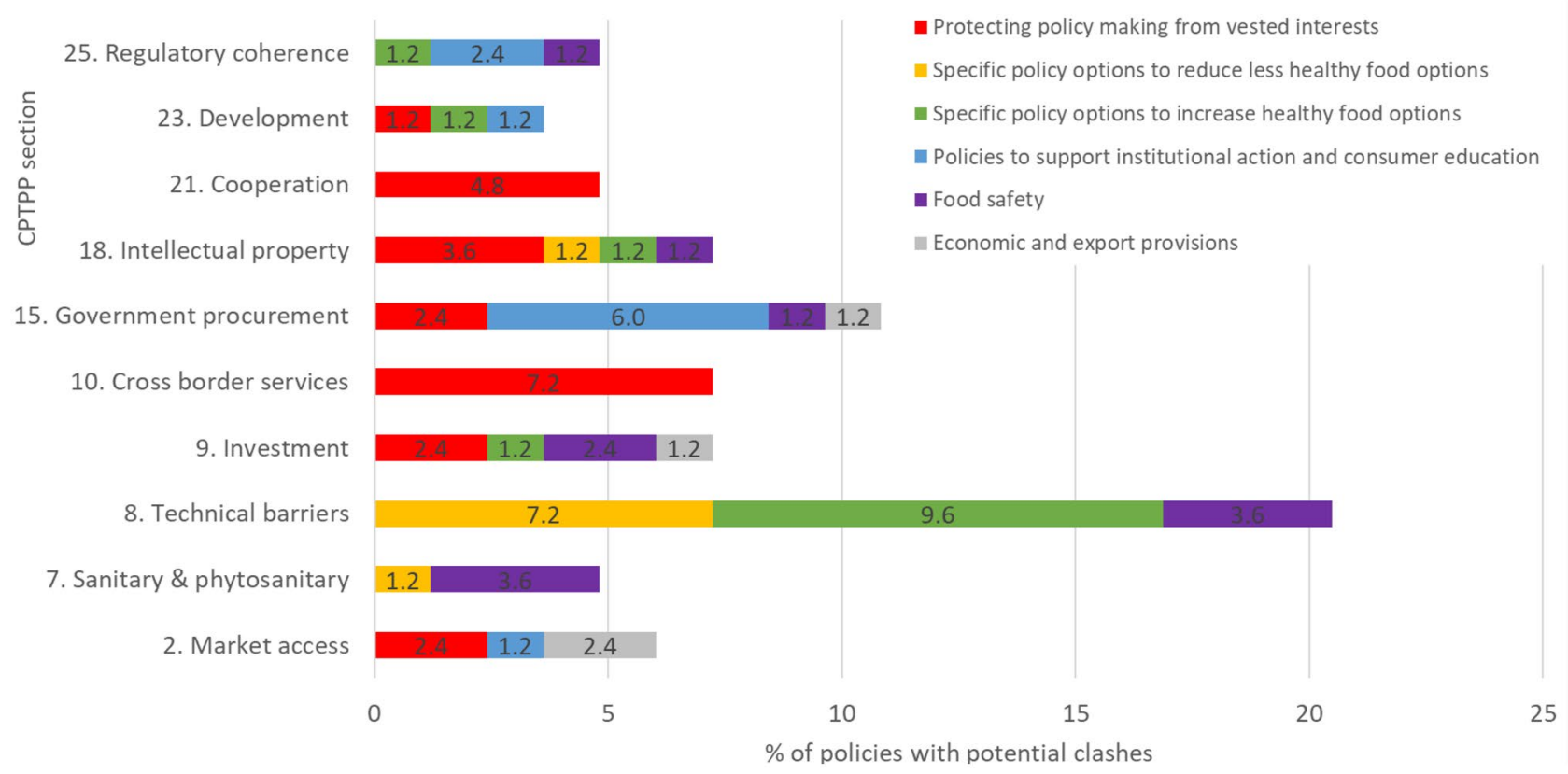

Fig. 2 Potential interactions between CPTPP sections and Vietnamese policy with nutrition relevance. Source: Authors' compilation from reviewed policies

encouragement of primary production of healthy foods; and the strengthening of both government service delivery and social mobilization for information dissemination (Decision 376/QD-TTg: Approve the National Strategy on prevention and control of cancer, cardiovascular diseases, diabetes, chronic obstructive pulmonary diseases, asthma and other $N C D s^{8}$ ).

The CPTPP $^{9}$ is in line with Vietnamese national trade policy priorities, and includes provisions to regulate sanitary and phytosanitary measures for food safety; regulate technical barriers to trade such as food labelling, including through allowing actors from other states-signatories to participate in national standard-setting; protect foreign investment and service suppliers through ensuring that foreign actors are accorded the same access as national actors; protect intellectual property; cooperate with and involve the private sector in policy; and promote regulatory coherence through involvement of interested parties in policy and regulatory decision making. The preamble explicitly recognises the right of states-parties to protect legitimate public welfare objectives, such as public health, through preserving the right to regulate in the public interest, notwithstanding the substantive sections of the agreement.

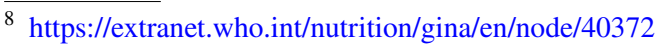

9 https://www.dfat.gov.au/trade/agreements/in-force/cptpp/officialdocuments/Pages/official-documents
}

\subsubsection{Interactions between written trade and nutrition policies}

Given the policy aims and provisions summarised above, it was highly likely that tensions would exist between the different sets of national government policy (broadly categorised as trade or nutrition). We identified 10 CPTPP sections with potential public health nutrition implications; and 50 nutrition, food or economic policies relevant to nutrition (60\% of those initially reviewed) that had one or more tensions with one or more CPTPP sections. Figure 2 shows the proportion and scope of interactions between the different CPTPP sections and Vietnamese policy related to public health nutrition identified in our review.

A majority of policy interactions were in sections of the CPTPP relating to technical barriers to trade (tensions with $21 \%$ of policies reviewed), and government procurement (tensions with $11 \%$ ). When categorised according to the WHO NCD guidelines, most tensions related to protecting policy making from vested interests (24\%), and specific policy options to increase healthy food options (15\%). Interactions relating to protecting policy from vested interests occurred throughout various CPTPP sections, but in particular under Sects. 10 (cross-border services), 18 (intellectual property) and 21 (cooperation). Interactions where the text of concern related to limiting unhealthy foods, or promoting healthy foods, largely occurred in Sect. 8 (technical barriers) of the CPTPP. Many interactions relating to supporting institutional actions or consumer education around nutrition 
occurred in Sect. 15 (government procurement), but in addition these interactions occurred in other sections, particularly where food policy was reviewed.

In the policies where no tensions were found, this was in some cases because there were clearly none (for instance, policy NUT_39; policy FOOD_7 - see Annex 1). In other cases, however, it was because the requirements, targets or criteria of the Vietnamese policies were not clear, meaning it was unclear whether the policy would be affected by provisions in the CPTPP. While the Vietnamese policies reviewed articulated clear priorities and objectives, there was often a lack of specific, explicit targets, which means interpretation by implementers may not always reflect best practice. For instance, policy NUT_17 aims to provide milk for children in schools, but does not contain any provision on the amount of sugar in the milk provided. Similarly, policy NUT_21 outlines the national strategy on NCD prevention, including technical guidelines for ensuring healthy nutrition, but does not contain provisions on salt or fat in foods. It is therefore difficult to know if either of these would be affected by provisions under technical barriers to trade.

This lack of specific criteria against which policy implementation or achievement could be evaluated made it challenging to assess some of the nutrition-related policies against the CPTPP trade policy, as it created room for interpretation away from established tenets of public health nutrition. Where targets or criteria were established for nutrition, these did not have legal implications if they were not achieved, whereas trade policy such as the CPTPP is legally binding between countries and investors, and includes scope for international arbitration of disputes. This creates incentives for prioritization of the provisions of international trade policy over domestic public health nutrition policy, for fear of sanctions.

In analysing the Vietnamese policy documents, it was clear that trade does not feature in nutrition policy, and where it features in food policy it is largely as issues around food safety or economic concerns relating to food imports and exports. Health does feature explicitly in the CPTPP, as broad-brush clauses allowing countries to protect legitimate public welfare objectives such as public health. These are curtailed however by caveats around the need for specific standards of evidence, and the weight of the provisions overall skews heavily towards economic concerns over health. There is therefore opportunity to strengthen written policy in the areas of both trade and public health nutrition, because it is at the interface of these different policy areas that tensions occur. In the following section, we use these tensions as a basis on which to explore with policy actors the processes through which these policies are created, and why this incoherence exists.

\subsection{Actors and interests in trade and nutrition policy processes}

\subsubsection{Actors}

The government executive in Vietnam (comprising the National Assembly, the Politbureau, and the President) sets the overall balance of policy direction for the country, and ultimately signs off policy and legislation. The government is advised by its Institute for Legislative Studies, and by individual ministries with sectoral mandates. The Ministry of Health $(\mathrm{MOH})$ has jurisdiction over nutrition and health policy in Vietnam, while the National Institute for Nutrition (NIN) has a role in technical policy advice and strategy. The Ministry of Industry and Trade (MOIT) leads trade negotiations and is responsible for trade aspects of imported and exported products, while other ministries are expected to have oversight of trade for their respective commodities in their corresponding sector. ${ }^{10}$ Outside of the government system, the United Nations (UN) and other international and local development partners (such as NGOs and financial donors) engage in specific policy issues according to their mandates; and business groups and national embassies lobby for their particular interests.

Where the government executive was mentioned in the interviews, Members of Parliament (MPs) in the National Assembly were framed as key actors to have on board on policy issues as the ultimate decision was in their hands (00_nu, 10_nu). Several nutrition actors drew on their recent policy process experience in successfully securing amendments to legislation on maternity leave and infant formula advertising restrictions in highlighting this. Beyond having to balance many competing priorities, some nutrition and agricultural respondents claimed that government actors often prioritised the interests of business over public health, being more concerned with GDP and economic interests. This bias was explained in a few ways. Firstly, it was portrayed as a matter of culture or routine, and that policymakers, in actively consulting with and taking the advice of business representatives more often and more systematically than with public health advocates, were just doing what they have always done (03_nu). A second explanation emphasised close ties between state actors and the business community, both in a formal policy sense (evident for instance through the MOH's embrace of public-private partnerships in the health system), and through the informal lobbying efforts of business actors (07_nu). Multinational corporations in particular were seen to have extensive resources and influence, allowing

\footnotetext{
${ }_{10}$ http://en.aecvcci.vn/tin-tuc-n4701/vietnam-importexport-report2018.htm
} 
them to conduct and disseminate their own (questionable) research, and sway state actors through 'gifts' (03_nu). Civil society representative 07_nu used the term 'corruption', claiming it was commonplace among state actors like MPs, and gave an example of an MP who was lobbying for the alcohol industry, later found to have financial ties to it.

Business was repeatedly described as having the funding, capacity and motivation to engage fully in trade negotiations, while civil society and even ministries often have none of these. For this reason, those with health or broader wellbeing objectives are often systematically excluded from trade talks. Notably, the only civil society representative in the respondent set, 07_nu, claims that they did not engage in any CPTPP processes due to lack of resources to do so. Like many self-organising business associations, they perhaps could have submitted opinions and engaged despite not being invited to do so, but they were not able to. Another lamented:

"So the battle field is unequal because on this side they have all the money, all the experiences, all the best lawyers, and on this side we only had the love for children, for women and we had the responsibility to make good policies, good law for our country." (00_nu)

Despite comments from a public sector trade actor (08_tr) who suggested that information was transparently available regarding negotiations via regular press conferences and media releases, other respondents commented on the opacity of trade deal negotiation processes. One nutrition actor working in a leadership role tasked with amending laws so that they are compliant with trade agreements (10_nu) stated that documents from negotiations were often not made available, and when they were, were difficult to find, were only in English, and were thousands of pages long, thus making accessibility difficult for law makers, civil society and the public. Documents were provided for information, rather than for consultation. This, it was implied, makes it difficult to think about, consider and act on how laws or policy needs to change, and how trade deals might impact nutrition.

Health and nutrition actors did not report deep or consistent engagement with trade policy processes. Respondents who did have experience or knowledge of trade deal negotiations mostly suggested that nutrition was not substantively considered in these discussions, or in consultation processes surrounding negotiations. 13_nu explained that even if nutrition actors are consulted by trade or commercial actors, their advice or input is not necessarily heeded. 02_nu similarly lamented that the potential impacts to business interests of a nutrition policy are taken seriously, while the nutritional impacts of a trade policy are not. A nutrition actor charged with policy activities lamented a double standard in which public health policy actors were expected to consider commercial factors in sectoral policy, while there was no reciprocal expectation (14_nu).

"In society, the health sector is not the most respected

voice. So, it's hard to raise the issue..." (14_nu)

Several trade actors however did feel that nutrition was considered in trade negotiations. 08_tr for instance offered a detailed description of the trade negotiation process, and claimed that nutrition was indeed considered, in the sense that different food products could be granted shorter or longer 'road maps' for integration. European milk was offered as an example of a product given a shorter road map in the past; this facilitated quicker availability to Vietnamese children. This was framed as a nutrition win by this actor, though other respondents, such as 07_nu, did not think the milk was getting to the right children or in the right forms. 11_tr also noted that some social and environmental issues are considered in trade negotiations as a result of the Sustainable Development Goals - although expressed only as 'declarative commitments' rather than anything obligatory. While nutrition is not explicitly included in the written CPTPP document, it was claimed that there is possible future scope for this, if it becomes a political priority as the other issues have.

Overall, the trade and nutrition actors were revealed as very separate in their interests and actions, very unequal in their resources and capacity, and with few opportunities for connection or motivations to create links. 12_tr suggested that it may not be normal practice for the different groups to talk to each other about their respective fields.

A final observation on actors is that citizen voice does not appear to be captured at all in trade negotiations. Media was for communication of key information to the public rather than for consultation. MOIT mentioned that they post information on their website for a period of time for the public's consultation, but it is unclear how many contributing ideas were received, and this process excludes a large proportion of Vietnam's population without sufficient literacy or internet access. The process for public consultation on the CPTPP was available, but not comprehensive.

\subsubsection{Narratives}

4.2.2.1 Nutrition narratives In understanding this separation of actors, it is important to understand how issues are framed by the different groups. Most nutrition actors recognised a wide range of nutrition problems (including the triple burden of stunting, obesity, and micronutrient deficiencies) and related drivers in Vietnam. Vietnamese nutrition policy, and Vietnamese nutrition actors (in particular $00_{-}$ nu; 10_nu), explicitly acknowledge that the social and economic drivers of a nutrition transition away from traditional diets and towards globalised diets and associated NCDs are 
in place, and that parts of the country have started down the dietary transition path. While issues of obesity and NCDs in urban areas (usually linked in interviews to increased consumption of fast food as well as 'chemicals' in foods) were described as a more modern problem, other issues were described as persistent, or re-emerging in the country after having not been a problem for some time, including stunting and goitre (00_nu). This group framed malnutrition in its various forms as a pressing issue which would follow classic nutrition transition trajectories, and that mitigating actions might need to be structural (such as in trade and taxes shaping food systems), as well as appealing to individual responsibility (such as nutrition education).

On the other hand, most agriculture and trade actors admitted to knowing little about nutrition. While some (01_ag; 05_ag; 11_tr) did recognise there to be some nutritional challenges in the country, they downplayed them, or did not speak about these issues, their causes or possible solutions very expansively. 09_tr for instance claimed that there were only pockets of malnourishment in rural areas and of obesity in cities, and that neither of these issues reached a risk threshold; measures like taxing sugar were seen as unfair and unnecessary to this respondent. 15_ag/ tr, who claimed there were no nutritional challenges in the country, was explicitly hostile towards any suggestion that structural measures such as taxation or restrictions on fast food, imports or advertising were appropriate ways to tackle current or future obesity. Nutrition issues were framed by this group as not a problem now (or yet), with nutrition as secondary to primary (economic, agriculture, trade) goals for the country at the moment. To the degree that nutrition was acknowledged to be a problem now or in the future, this was framed more as a matter of nutrition education and social awareness.

"So, we need to raise awareness in families, school and, the community. When it comes to advising and awareness, there must be a set of criteria or guidelines in communication through television, press or through school without restrictions. But somehow, we have to ensure the proper nutrition for families, students. We can't forbid people from eating something in today's society." (15_ag/tr)

Food safety was perhaps of the highest priority for agricultural actors in relation to nutrition. Like agricultural actors, some trade actors also acknowledged food safety as relating to nutrition. $15 \_a g / t r$, who was largely dismissive of nutrition problems in Vietnam, stressed that ensuring safe food value chains was more important than focusing on nutrition, as did others. The lack of coordination or connection among agriculture and nutrition actors and structures was also made clear on this issue.
4.2.2.2 Trade narratives There was a clear narrative from the trade and agriculture respondents on free trade as positive, with a logic of economic growth leading to better nutrition through increased incomes alongside allowing the import of more and different foods, with all or more food generally being good, and choice as key. While some respondents recognised trade-offs whereby widening inequalities have left some sections of society behind, free trade advocates felt that it was the role of social policy to deal with this (nutrition education, social protection), not changes to trade policy.

A feature of the position of nutrition actors on trade was lack of clarity and uncertainty. Despite a laundry list of frustrations expressed by nutrition actors commenting on domestic public health policy in the face of more influential commercial priorities and actors, international trade in its broad economic sense was regarded as positive for nutrition by some of these actors. Most nutrition actors had no clear position on free trade beyond noting changes to trade as a potential policy lever for improving food supply for healthy diets, and very few mentioned more nuanced aspects of closing down or opening up policy space for nutrition. 03_nu mentioned the advertisement of unhealthy products like soda, while poor regulation and enforcement around product quality in the informal sector was mentioned by 13_nu. As well as "rolling out a red carpet" for "humanitarian industries" such as organic foods, 07_nu also commented that "barbed wire" should be erected against industries and products damaging to public health.

4.2.2.3 Conflicting narratives In terms of internal narratives (how sectors described their own ideas, interests and agendas), with relation to trade and nutrition, there was a clear separation between two different groups. A trade and agriculture narrative focused on the importance of markets (national and global) for goods; development of the agricultural sector in Vietnam with a focus on household and national income; and, with an eye to nutrition, the role of trade in facilitating greater food choice through making different foods available, and food safety. A nutrition narrative was clearly distinct, framing poor nutrition outcomes along a continuum from under- to over-nutrition as the issue (rather than economic development) but engaging very little with issues of trade.

Discussions of the role of trade in shaping nutrition therefore start with different groups having very different framings of the problem and its potential solutions: The public health group feels broadly that government should be intervening in trade itself, but only frames this as shaping the food environment. The trade group feels broadly that free trade should be left well alone to provide all kinds of goods, with the role of government limited to public health 
Table 2 Identifying coalitions in Vietnamese trade policy processes

\begin{tabular}{|c|c|c|c|c|c|c|c|}
\hline & Actors & Interests & Beliefs and ideologies & Narratives & Policy positions & Actions and engagement & Power and influence \\
\hline \multirow[t]{4}{*}{\begin{tabular}{|l|}
$\begin{array}{l}\text { Trade } \\
\text { coalition }\end{array}$ \\
\end{tabular}} & Government executive & $\begin{array}{l}\text { Economic growth; } \\
\text { population welbeing }\end{array}$ & $\begin{array}{l}\text { Opening up to trade; } \\
\text { social cohesion }\end{array}$ & $\begin{array}{l}\text { Need to balance } \\
\text { economic and social } \\
\text { objectives }\end{array}$ & $\begin{array}{l}\text { Economic growth } \\
\text { through free trade. } \\
\text { Social policy for } \\
\text { wellbeing. }\end{array}$ & $\begin{array}{l}\text { Pushes both agendas, } \\
\text { but unequally }\end{array}$ & $\begin{array}{l}\text { Ultimate decision- } \\
\text { making power }\end{array}$ \\
\hline & MOIT & $\begin{array}{l}\text { Economic growth; trade; } \\
\text { funding }\end{array}$ & \multirow{3}{*}{$\begin{array}{l}\text { Nutrition is not a } \\
\text { problem }\end{array}$} & \multirow{2}{*}{$\begin{array}{l}\text { Free trade improves } \\
\text { nutrition by default; no } \\
\text { acknowledgement of } \\
\text { trade-offs or future } \\
\text { issues }\end{array}$} & \multirow{3}{*}{\begin{tabular}{|l} 
Free trade \\
Poverty reduction \\
Food safety \\
$\begin{array}{l}\text { No structural } \\
\text { intervention into food or } \\
\text { nutrition specifically; } \\
\text { rather social security and } \\
\text { education }\end{array}$
\end{tabular}} & \multirow{2}{*}{$\begin{array}{l}\text { Leading the process } \\
\text { Business as usual }\end{array}$} & \multirow{3}{*}{$\begin{array}{l}\text { Invited/consulted } \\
\text { Resource-rich (Business) } \\
\text { Historically dominant }\end{array}$} \\
\hline & MOA & $\begin{array}{l}\text { Expanding agriculture; } \\
\text { link to markets; funding }\end{array}$ & & & & & \\
\hline & $\begin{array}{l}\text { Business and lobby } \\
\text { groups }\end{array}$ & $\begin{array}{l}\text { Profit; sustainable } \\
\text { business }\end{array}$ & & $\begin{array}{l}\text { Food safety as key trade } \\
\text { issue, priority; public } \\
\text { health is fine } \\
\text { Social safety nets and } \\
\text { education take care of } \\
\text { nutrition }\end{array}$ & & $\begin{array}{l}\text { Highly engaged in } \\
\text { process } \\
\text { Significant funds }\end{array}$ & \\
\hline \multirow[t]{6}{*}{$\begin{array}{l}\text { Nutrition } \\
\text { coalition }\end{array}$} & $\mathrm{MOH}$ & $\begin{array}{l}\text { Healthy population; } \\
\text { funding }\end{array}$ & \multirow{6}{*}{$\begin{array}{l}\text { Nutrition is a pressing } \\
\text { problem } \\
\text { No clear trade ideology; } \\
\text { doesn't factor into their } \\
\text { work, even if individuals } \\
\text { take positions }\end{array}$} & \multirow{6}{*}{$\begin{array}{l}\text { Concerning health data } \\
\text { needs attention } \\
\text { Trade is a possible route } \\
\text { to positive change }\end{array}$} & \multirow{6}{*}{$\begin{array}{l}\text { Poverty reduction } \\
\text { Consider nutrition and } \\
\text { health explicitly in trade, } \\
\text { alongside social policy }\end{array}$} & \multirow{3}{*}{$\begin{array}{l}\text { Occasional input into } \\
\text { trade debates. }\end{array}$} & \multirow{3}{*}{ Uninvited } \\
\hline & NIN (hardly mentioned) & $\begin{array}{l}\text { Well-nourished } \\
\text { population; funding }\end{array}$ & & & & & \\
\hline & Policy research groups & Use of evidence; funding & & & & & \\
\hline & UN & \multirow{3}{*}{$\begin{array}{l}\text { Population wellbeing; } \\
\text { inclusion and } \\
\text { engagement }\end{array}$} & & & & $\mid \begin{array}{l}\text { Engaged in some aspects } \\
\text { but not overall engaged } \\
\text { in trade negotiations }\end{array}$ & \multirow{3}{*}{$\begin{array}{l}\text { Advocates rather than } \\
\text { power players }\end{array}$} \\
\hline & Civil society (int) & & & & & & \\
\hline & Civil society (national) & & & & & No clear engagement & \\
\hline
\end{tabular}

MOIT: Ministry of Trade and Industry. MOA: Ministry of Agriculture. MOH: Ministry of Health. NIN: National Institute of Nutrition. UN: United Nations

education and social protection. These narratives are not entirely divergent (nutrition actors also aim for poverty alleviation for instance; and economic development from trade aims at broad household welfare), but are divergent on whether trade should be a policy lever for nutrition specifically, or whether unfettered free trade should be encouraged and social policy should mop up any negative externalities.

Different beliefs on the issues feed clearly into a divergent set of narratives on the role of trade and the importance of nutrition in policy. These narratives link strongly to interests and policy priorities, and the clearest and therefore most dominant narratives on trade are those from the trade and agriculture actors. There is a lack of clarity on issues and solutions on both sides that do not meet in the middle: Nutrition actors are generally not trade-literate, and lack clarity on what public health nutrition wants or needs trade to do; while trade and agriculture actors are generally not knowledgeable about nutrition issues and their determinants, and the potential role of trade in solutions.

\subsection{Advocacy coalitions in trade and nutrition}

From analysis of the actors and narratives outlined above in the Vietnamese context, it was clear that there were two broad coalitions of actors at work in the Vietnamese trade policy process as relates to nutrition (Table 2). One, which we have named the Trade Coalition, comprises actors who clearly adhere to free trade ideology, with interests in expanding markets for agricultural produce, promoting economic growth, and promoting business. This coalition largely believes that free trade improves nutrition by default, without acknowledgement of any potential down-sides of trade for nutrition and health, and hence takes a policy position of no structural intervention into trade in support of nutrition policy, but rather advocates social protection and nutrition education to clear up any issues that the trade and economic agenda might ignore or create for nutrition.

The other, which we have named the Nutrition Coalition, has a clear focus on healthy, well-nourished populations as part of broader wellbeing outcomes. While actors in this coalition were clear on their public health nutrition goals and the policies required to achieve them, it was striking that this coalition had no clear ideology on the issue of trade and how it might affect (or be used to enhance) nutrition. Some actors had given some thought to whether trade might be a route to positive change, and most felt that nutrition and health should be explicitly considered in trade policy alongside broader poverty reduction and economic concerns. But there were no specific policy positions or inputs forthcoming from this coalition relating to trade.

The Nutrition Coalition largely comprises actors from the Ministry of Health (MOH), National Institute of nutrition (NIN) (though NIN's role was hardly mentioned), policy research groups, the UN, and national and international civil society. The Trade Coalition largely comprises actors from the Ministry of Industry and Trade (MOIT), Ministry 
of Agriculture (MOA), and business and lobby groups. We have also placed the government executive tentatively within the trade coalition. The Vietnamese government holds a particular position in needing to balance economic growth and poverty reduction objectives with broader population welfare and wellbeing, and is responsible for policy decisions spanning all sides of the issue, including free trade for economic growth and social policy for wellbeing. We have included the government under the Trade Coalition because although government promotes and funds both agendas, it does so unequally, and we find that on balance the current government favours trade over nutrition based on policy funding, policy process engagement, and strength and legal enforceability of policies. Lastly, though we have grouped actors under their ministry or sector, there are of course a broad range of individual actors within each institution who will hold more nuanced views and beliefs on the topic of trade and nutrition; our coalitions are based on patterns in the data, and do not capture this nuance well.

\section{Discussion}

In this study, we analysed potential impacts of the 2018 CPTPP trade policy on policy space for public health nutrition in Vietnam, and investigated policy actor engagement and understanding of these potential impacts. We find that in Vietnam, policy space for public health nutrition is potentially constrained by tensions with the CPTPP, as has been seen with other trade agreements in other countries (Thow et al., 2010). Similar to previous research in other contexts, we find a clear ideological division between those working on trade and those working on public health nutrition - in terms of strength of support for free trade and in terms of views on the priority of public health nutrition - and in turn the narratives adhered to, and the policies advocated and pursued by different groups (Béné et al., 2019; Thow et al., 2018).

\subsection{Policy space: Actors and narratives}

We extend previous work in the area of trade and nutrition by explaining these actor groupings in the policy space through the theory of advocacy coalitions (Sabatier \& Weible, 2016). Actors in a policy sub-system may act as individuals or organizations, but grouping into networks, coalitions and alliances allows actors to also act collectively in their policy advocacy, sharing attributes such as expertise, experience and credibility for what is generally agreed to be increased effectiveness in pursuing their aims (Mooji \& de Vos, 2003). The Advocacy Coalition Framework (Weible \& Sabatier, 2007) explains change in policy as following change in the belief systems of dominant coalitions, such as the trade coalition here. Belief changes in turn stem from either major events external to the sub-system, such as changes in the policy environment to which coalitions must adapt or from which they can learn; or internal shocks within a sub-system, where accumulation of learning demonstrates the policy core beliefs of a dominant coalition to be failing, or those of a challenging coalition to be confirmed (Sabatier \& Jenkins-Smith, 1993). Previous literature has found nutrition policy advocacy coalitions at odds with other policy communities in different countries, and this work found that shared evidence and mutual understanding could bring about some level of belief change that might lead to a coming together of coalitions to tackle both policy issues (Harris, 2019; Thow et al., 2016). Creating coalitions actively according to world-view or interests (rather than falling into them passively based on sector) might be fruitful in creating alliances specifically to work on the issue of trade and nutrition (Friel et al., 2019).

\subsection{Policy space: Context and issues}

These coalitions have emerged through the recent history of Vietnam, as on the one hand an emerging economy looking to engage economically with powerful neighbours and allies, and on the other hand a country with relatively strong focus on social policy such as health (Baulch, 2016). In Vietnam, we see diets changing in line with the nutrition transition (Harris et al., 2020), and conceptually connect this with shifts in the food and policy environment through trade agreements that have been observed elsewhere (Werner et al., 2019). These changes in the nutrition profile of the country were however either not recognised or not prioritised by trade actors in this study, and where they were, they were often felt to be best tackled through routes other than trade given the primacy of economic goals.

Narratives of neoliberal market economics as being non-negotiable, and nutrition being an issue of individual responsibility, are regularly seen in work assessing these processes (Friel et al., 2020), as seen in the trade coalition in our work. Other assessments of narratives around trade and food in Vietnam have found that none of the narratives are around health or nutrition, rather everything is about aspects of economics, from protecting farmers and small business, to economic growth, to price stabilisation (Béné et al., 2020). In the other direction, engaging the trade coalition in discussions around nutrition issues may be difficult, as previous work has shown that trade experts in Vietnam see themselves as having engaged already in food system debates, whether or not they class themselves as knowledgeable about those debates; and trade actors feel that the current food system agenda (including trade) already matches reality in terms of food needs (Béné et al., 2020). The evidence in this paper, and evidence on changing diets in 
Vietnam (Harris et al., 2020), may be an entry point to discussions aimed at clarifying or changing these narratives.

\subsection{Policy space: Power}

Differences in narratives underpinning discussion of tradenutrition linkages include conflicting world views embedded in policy paradigms, and competing interest groups with different power in the process (Friel et al., 2019). A lack of discursive power to move beyond market framings has been observed to lead to a privileging of trade over health, and as health is not seen as a powerful sector, it is not generally invited to the table in trade negotiations (Friel et al., 2019; Thow et al., 2018). This means that only one of these coalitions (and therefore one of these narratives and policy positions) routinely takes a seat at the table in trade policy negotiations, and therefore has a voice in these. In general in Vietnam, both business and central government actors have a strong food systems role, with MOIT seen as moderately influential but less than the PolitBureau; large firms are seen as more influential than MOIT; and civil society is seen to be marginalised (Béné et al., 2020). Even within government however, there are different levels of engagement in trade policy processes: According to government websites, all ministries have had their implementation plan for the CPTPP since 2019 except for the Ministry of Health, ${ }^{11}$ suggesting that the $\mathrm{MOH}$ was not highly involved in the CPTPP process. We can't say from our data whether this is due to structural limitations or a choice not to engage, but practical considerations such as levels of resources and information asymmetries have been seen to block public interest groups in other trade negotiation contexts (Friel et al., 2020).

Understanding and acknowledging the different spaces and forms of power at work in barring or facilitating different actors to engage in trade policy negotiations allows for addressing these issues and securing engagement for nontraditional actors with public health and nutrition concerns (Friel et al., 2020; Gaventa, 2006). We suggest that a focus on understanding power in the closed spaces of trade policy negotiation - from unbalanced resources across actors, to promoting dominant ideologies as the norm - is necessary in order to intervene in favour of public welfare, including nutrition. Future work should engage more explicitly with understanding power in trade and nutrition policy processes.

\subsection{Implications for policy space}

In our interpretation of policy space (Fig. 1), the space for social welfare objectives such as nutrition is expanded or

\footnotetext{
11 http://cptpp.moit.gov.vn/default.aspx?page=overview\&category_ id=ae16c761-9aca-4f55-b3e8-f3e43979bb59).
}

constrained through support or opposition in the areas of actor influence, narratives and agendas, and the characteristics of the policy issues at stake, within their broader political, institutional and social context. In Vietnam, the broader context is one of stronger alignment to global trade, with multiple large agreements in place or in process - but with political commitment to aspects of health in policy and government funding as part of the discourse of national development. This implies that there is opportunity to raise the issue of tensions between trade and nutrition policy and to expand policy space for nutrition, but the actor interviews show clearly that these two issues have not been considered together in policy processes so far. The interests, beliefs and narratives of the two broad coalitions - trade and nutrition - are evolving separately, and the lack of consideration of nutrition in trade negotiation processes (or of trade issues in nutrition policy) has meant that multiple tensions exist between written policy documents. Given the legal primacy of international free trade agreements over national policy documents, the tensions are likely to resolve in the interests of economics rather than broader health and social welfare considerations, if tested.

We conclude from our analysis that the policy space for nutrition in Vietnam has important potential constraints from the CPTPP trade policy, and that the trade and nutrition coalitions need to interact more regularly and constructively in order to foresee where these tensions will arise in practice, and create plans for their mitigation. Tensions or connections between trade and social policy occur in multiple fields, and nutrition can learn from other social or environmental sectors. In general, advocacy on behalf of the social sector in question will be needed if these issues are to be considered in trade negotiations, as these are not included by default (as seen in our interviews with the trade policy coalition). It has been found that linking trade and social causes is motivated by strategic action by substantial interested parties (Lechner, 2016). Previous work however has found that trade policy negotiations are opaque, exclusionary, and only allow input from those 'in the know', with poor accountability to citizens (Friel et al., 2019), so it is likely that nutrition coalition actors would have to work hard to be included in future negotiations, including educating themselves about trade policy and processes and finding powerful advocates to work with (Friel et al., 2020). Public health advocates should beware of false friends, however: Recent work in China has found a business lobby group masquerading as a health research organisation inserting their own damaging narratives into nutrition debates, and thus leading to corporate biasing of health policy which has been largely invisible even to other public health actors (Greenhalgh, 2019a, b). The business lobby group active in China, International Life Sciences Institute (ILSI), also has members among nutrition actors in Vietnam. Shifting the balance of inclusion in 
trade policy processes is critical because trade agreements are binding and nutrition policies are not (Friel et al., 2020).

\subsection{Methodological reflections}

This qualitative case study is the first we are aware of to analyse, using established pubic policy theory, the connections and tensions between free trade agreements and national public nutrition policy in Vietnam. Its strengths lie in the application of multiple public policy frameworks to explain the findings and compare them with other case-contexts, extending and strengthening work on trade-nutrition linkages, and on advocacy coalitions in nutrition policy processes. We compare our findings to other trade-nutrition literature, and find similarities with policy tensions, actor coalitions, and sectoral narratives in other contexts, which suggests that there are patterns in the ways that trade and nutrition interact. The literature is building evidence as to what extent these patterns are generalizable or context-specific, and our paper adds to that debate for the case of the CPTPP in Vietnam. The study adds to global evidence on the importance of pro-active engagement on behalf of nutrition actors in trade policy negotiations, and suggests ways forward for Vietnam.

We found in this research that relying on a single framework or heuristic to frame the study would omit important information about some aspect of the policy process, so we combined ideas from multiple frameworks that describe aspects of agenda setting and policy space (Grindle \& Thomas, 1991; Keeley \& Scoones, 1999; Shiffman, 2007). Each of these looked at aspects of context, issues, actors, and narratives; combining these provided a more rounded understanding of the policy process on which to build our study. We found that this combination of political science theory early-on in the study structured the study to look at a broader range of issues than a single framework would have allowed.

Understanding our findings required application of midrange policy theory, and in this case the theory of Advocacy Coalitions (Sabatier \& Weible, 2007) explained our empirical data most closely. Previous work on advocacy coalitions in nutrition policy processes has found that the theory as originally elaborated likely did not pay enough attention to the interests (economic or otherwise) of different actors, alongside its focus on their beliefs (Harris, 2019). We therefore tried in this work to explicitly include notions of actor interests alongside beliefs in shaping their policy positions. We find that actor interests and beliefs are connected in that they push an actor in the same policy direction, but we cannot determine the direction of association: Do existing beliefs shape whether an actor enters an organisation with certain interests; or does training towards a position in an organisation with certain interests shape actor beliefs over time? Either way, actor beliefs and interests align in shaping their core narratives and policy positions in this study. The extension of the Advocacy Coalitions Framework towards incorporating a focus on interests will need to address this issue in further research.

This study has similar limitations to other qualitative policy process studies, in that the respondents were necessarily a sub-set of policy actors, and our findings are based on their views. We feel we captured a good cross-section of views through our interviews however, and our findings chime with similar studies elsewhere. We did not look at how the ratification of the CPTPP changed the situation already in place through existing trade policy in Vietnam, but our findings can be seen as a baseline; no other trade policy could reduce the impacts of the CPTPP on nutrition policy space, only add to them. The same policy analysis could be replicated for other trade policies, but likely a similar set of potential issues would arise; Vietnam already has several free trade agreements, so the CPTPP extends these issues to a broader range of powerful countries, rather than bringing these issues fresh to Vietnam.

\section{Conclusions}

While trade agreements are an important part of running an economy, and have positives for public health nutrition as well as negatives, economic issues are not the only legitimate concern of governments (Friel et al., 2020), but sit alongside the need to improve the physical and social wellbeing of their population. This study adds empirical and theoretically-grounded evidence from Vietnam on the impacts of a large free trade agreement on multiple aspects of public health nutrition policy space.

The CPTPP and Vietnam's next free trade policy, the Regional Comprehensive Economic Partnership (RECEP) signed in November 2020, have garnered attention as 'mega free trade agreements' with the potential to lead to a Free Trade Area of Asia-Pacific (FTAAP) (Urata, 2018). This means that more negotiations, with even more powerful economies, are likely in Vietnam in coming years, and coalitions advocating public health need to learn fast how to bring nutrition considerations squarely into these negotiations to address trade as an important aspect of the emerging nutrition transition.

\section{Annex 1}

Cross-referencing CPTPP section and national policy. 


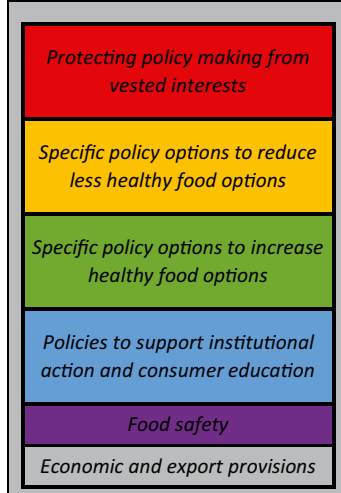

$\uparrow$ LEGEND
VIETNAMESE POLICY â

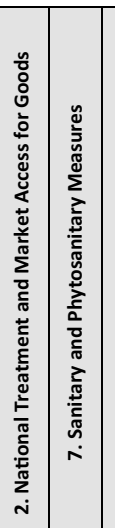

CPTPP SECTION $\rightarrow$

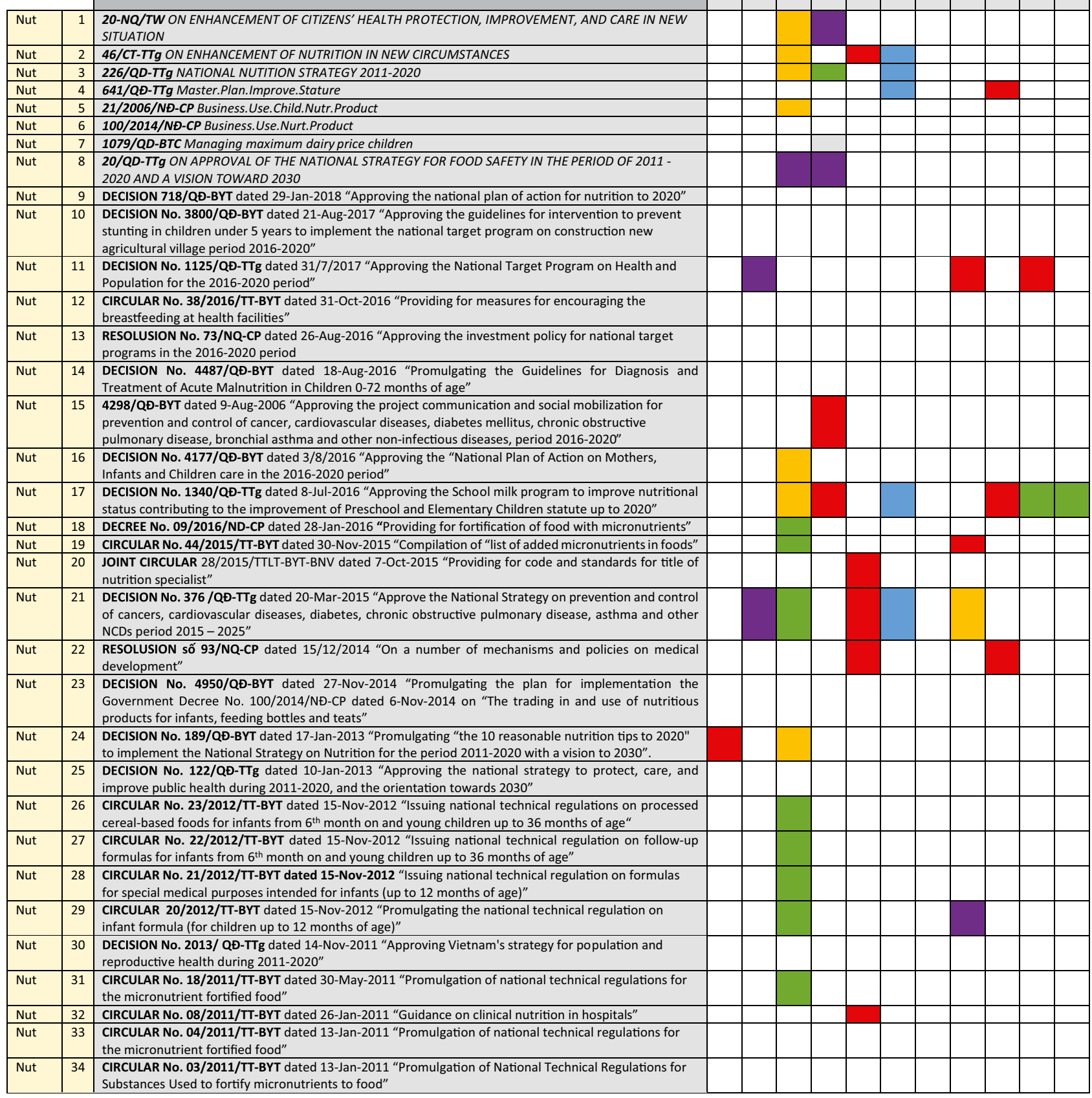




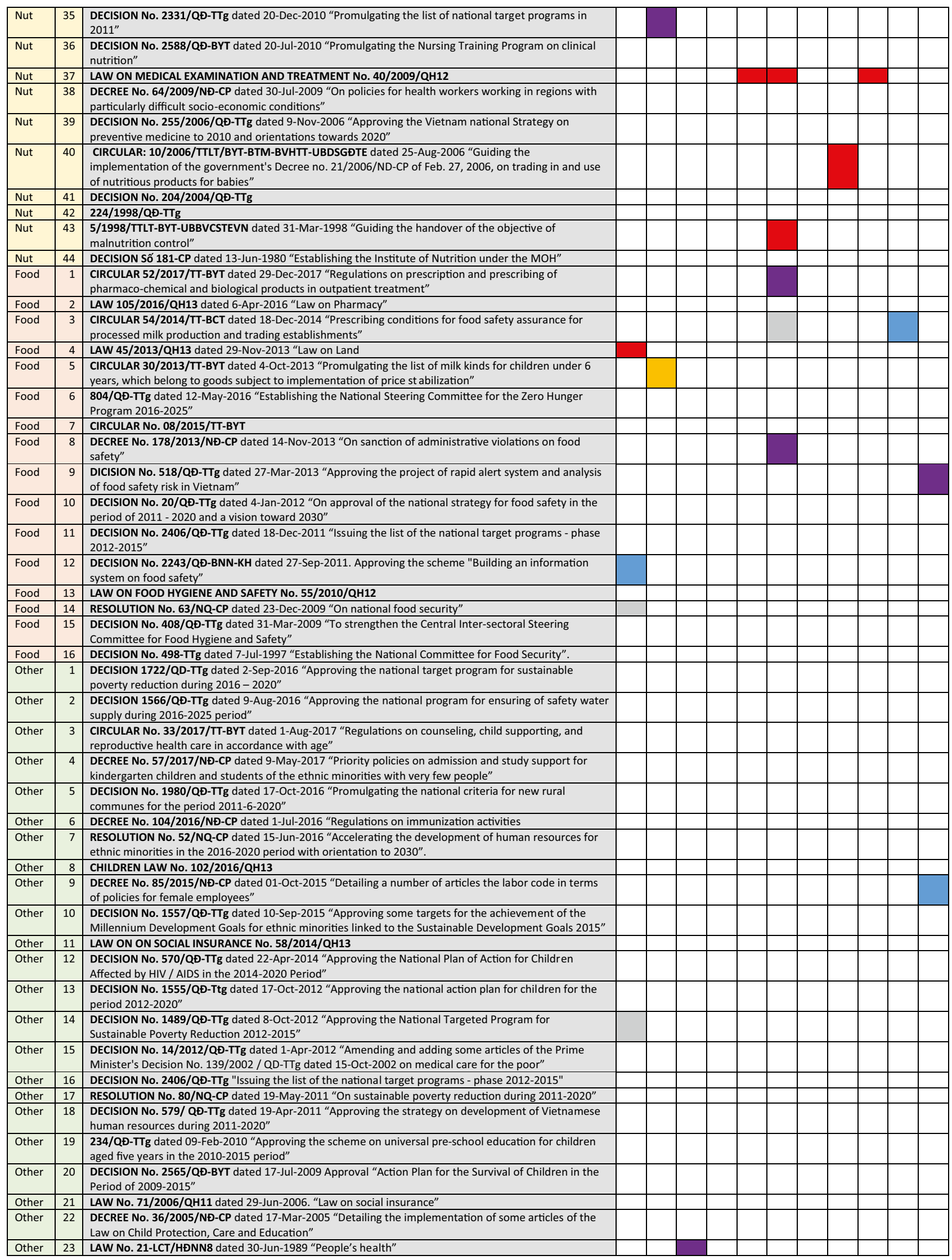




\section{Declarations}

Conflict of interest The authors note no conflict of interest in the preparation of this manuscript.

Open Access This article is licensed under a Creative Commons Attribution 4.0 International License, which permits use, sharing, adaptation, distribution and reproduction in any medium or format, as long as you give appropriate credit to the original author(s) and the source, provide a link to the Creative Commons licence, and indicate if changes were made. The images or other third party material in this article are included in the article's Creative Commons licence, unless indicated otherwise in a credit line to the material. If material is not included in the article's Creative Commons licence and your intended use is not permitted by statutory regulation or exceeds the permitted use, you will need to obtain permission directly from the copyright holder. To view a copy of this licence, visit http://creativecommons.org/licenses/by/4.0/.

\section{References}

Barlow, P., McKee, M., Basu, S., \& Stuckler, D. (2017). The health impact of trade and investment agreements: A quantitative systematic review and network co-citation analysis. Globalization and Health, 13(1), 13.

Baulch, B. (2016). Explaining catch-up in human development: A political economy comparisons on the Philippines and Viet Nam Since 1986. The Kellogg Institute for International Studies: Working Paper, 412.

Béné, C., Kawarazuka, N., Pham, H., Haan, Sd., Tuyen, H., Thi, D. T., \& Dang, C. (2020). Policy framing and crisis narratives around food safety in Vietnam. Environment and Planning e: Nature and Space, 4(3), 985-1009.

Béné, C., Oosterveer, P., Lamotte, L., Brouwer, I. D., de Haan, S., Prager, S. D., Talsma, E. F., \& Khoury, C. K. (2019). When food systems meet sustainability - Current narratives and implications for actions. World Development, 113, 116-130.

Buse, K., Aftab, W., Akhter, S., Phuong, L. B., Chemli, H., Dahal, M., Feroz, A., Hofiani, S., Pradhan, N. A., \& Anwar, I. (2020). The state of diet-related NCD policies in Afghanistan, Bangladesh, Nepal, Pakistan, Tunisia and Vietnam: A comparative assessment that introduces a 'policy cube' approach. Health Policy and Planning, 35(5), 503-521.

Crichton, J. (2008). Changing fortunes: Analysis of fluctuating policy space for family planning in Kenya. Health Policy and Planning, 23(5), 339-350.

Development Initiatives. (2020a). 2020 Global Nutrition Report: Action on equity to end malnutrition. Bristol, UK, Development Initiatives.

Development Initiatives. (2020b). Vietnam country profile. Global Nutrition Reort 2020. Development Initiatives. Bristol, UK.

Friel, S., Baker, P., Thow, A. -M., Gleeson, D., Townsend, B., \& Schram, A. (2019). An exposé of the realpolitik of trade negotiations: Implications for population nutrition. Public Health Nutrition, 22(16), 3083-3091.

Friel, S., Schram, A., \& Townsend, B. (2020). The nexus between international trade, food systems, malnutrition and climate change. Nature Food, 1(1), 51-58

Gaventa, J. (2006). Finding the spaces for change: A power analysis. IDS Bulletin, 37(6), 23-33.

Global Panel on Agriculture and Food Systems for Nutrition. (2016). Food systems and diets: Facing the challenges of the 21st Century. UK, Global Panel.

Global Panel on Agriculture and Food Systems for Nutrition. (2020). Rethinking trade policies to support healthier diets. Policy brief no. 13. London, UK.
Greenberg, H., \& Shiau, S. (2014). The vulnerability of being ill informed: The trans-pacific partnership agreement and global public health. Journal of Public Health, 36(3), 355-357.

Greenhalgh, S. (2019). Making China safe for Coke: how Coca-Cola shaped obesity science and policy in China. BMJ Feature 364.

Greenhalgh, S. (2019b). Soda industry influence on obesity science and policy in China. Journal of Public Health Policy, 40(1), 5-16.

Grindle, M. S., \& Thomas, J. W. (1991). Public choices and policy change: The political economy of reform in developing countries. Johns Hopkins University Press.

Harris, J. (2019). Coalitions of the willing? Advocacy coalitions and the transfer of nutrition policy to Zambia. Health Policy and Planning, 34(3), 207-215.

Harris, J., Huynh, P., Nguyen, H. T., Hoang, N., Mai, L. T., Tuyen, L. D., \& Nguyen, P. H. (2021). Nobody left behind? Equity and the drivers of stunting reduction in Vietnamese populations. Food Security, 13(4), 803-818.

Harris, J., Nguyen, P., To, Q., Frongillo, E., \& Menon, P. (2016). Progress in improving provincial plans for nutrition through targeted technical assistance and local advocacy in Vietnam. Health Policy and Planning., 31(10), 1333-1341.

Harris, J., Nguyen, P. H., Tran, L. M., \& Huynh, P. N. (2020). Nutrition transition in Vietnam: Changing food supply, food prices, household consumption, diet and nutrition outcomes. Food Security., 12(5), $1141-1155$.

Hirvonen, K., Bai, Y., Headey, D., \& Masters, W. A. (2019). Cost and affordability of the EAT-Lancet diet in 159 countries. Lancet, 8(1), e59-e66.

Jaffee, S., Henson, S., Unnevehr, L., Grace, D., \& Cassou, E. (2018). The safe food imperative: Accelerating progress in low-and middleincome countries. The World Bank.

Keeley, J., \& Scoones, I. (1999). Understanding Environmental Policy Processes: A Review. IDS Working Paper 89. Brighton, IDS.

Lechner, L. (2016). The domestic battle over the design of non-trade issues in preferential trade agreements. Review of International Political Economy, 23(5), 840-871.

Mai, T. M. T., Pham, N. O., Tran, T. M. H., Baker, P., Gallegos, D., Do, T. N. D., van der Pols, J. C., \& Jordan, S. J. (2020). The double burden of malnutrition in Vietnamese school-aged children and adolescents: A rapid shift over a decade in Ho Chi Minh City. European Journal of Clinical Nutrition, 74(10), 1448-1456.

Mbuya, N. V., Atwood, S. J., \& Huynh, P. N. (2019). Nutrition Situation in Ethnic Minority Populations. World Bank report (unpublished).

Mitchell, A., \& Sheargold, E. (2015). Protecting the autonomy of states to enact tobacco control measures under trade and investment agreements. Tobacco Control, 24(e2), e147-e153.

Mooji, J., de Vos, V. (2003). Policy processes: An annotated bibliography on policy processes, with particular emphasis on India. Working paper 221. London, UK, Overseas Development Institute.

Paarlberg, R. (2012). Governing the dietary transition: linking agriculture, nutrition, and health. In: S. Fan \& R. Pandya-Lorch (Eds.), Reshaping Agriculture for Nutrition and Health (pp.191-199).

Popkin, B. M. (2017). Relationship between shifts in food system dynamics and acceleration of the global nutrition transition. Nutrition Reviews, 75(2), 73-82.

Popkin, B. M., Corvalan, C., \& Grummer-Strawn, L. M. (2020). Dynamics of the double burden of malnutrition and the changing nutrition reality. The Lancet, 395(10217), 65-74.

Raneri, J. E., Kennedy, G., Nguyen, T., Wertheim-Heck, S., Do, H., de Haan, S., \& Phuong, N. (2019). Determining key research areas for healthier diets and sustainable food systems in Viet Nam. Intl Food Policy Res Inst.

Sabatier, P. A., \& Jenkins-Smith, H. C. (1993). Policy Change and Learning: An Advocacy Coalition Approach (Theoretical Lenses on Public Policy). Westview Press. 
Sabatier, P. A., \& Weible, C. M. (2007). The advocacy coalition framework: Innovations and clarifications. In: P. A. Sabatier (Ed.), Theories of the policy process (2nd ed., pp. 189-217).

Sabatier, P. A., \& Weible, C. M. (2016). The advocacy coalition framework: Innovations and clarifications. In: P. A. Sabatier (Ed.), Theories of the policy process (2nd ed., pp. 189-217).

Shiffman, J. (2007). Generating Political Priority for Maternal Mortality Reduction in 5 Developing Countries. American Journal of Public Health, 97, 796-803.

Swinburn, B. A., Kraak, V. I., Allender, S., Atkins, V. J., Baker, P. I., Bogard, J. R., Brinsden, H., Calvillo, A., De Schutter, O., \& Devarajan, R. (2019). The global syndemic of obesity, undernutrition, and climate change: The Lancet Commission report. The Lancet, 393(10173), 791-846.

Thow, A. M. (2009). Trade liberalisation and the nutrition transition: Mapping the pathways for public health nutritionists. Public Health Nutrition, 12(11), 2150-2158.

Thow, A. M., Greenberg, S., Hara, M., Friel, S., \& Sanders, D. (2018). Improving policy coherence for food security and nutrition in South Africa: A qualitative policy analysis. Food Security, 10(4), 1105-1130.

Thow, A. M., Kadiyala, S., Khandelwal, S., Menon, P., Downs, S., \& Reddy, K. S. (2016). Toward food policy for the dual burden of malnutrition: An exploratory policy space analysis in India. Food and Nutrition Bulletin, 37(3), 261-274.

Thow, A. M., Snowdon, W., Labonté, R., Gleeson, D., Stuckler, D., Hattersley, L., Schram, A., Kay, A., \& Friel, S. (2015). Will the next generation of preferential trade and investment agreements undermine prevention of noncommunicable diseases? A prospective policy analysis of the Trans Pacific Partnership Agreement. Health Policy, 119(1), 88-96.

Thow, A. M., Swinburn, B., Colagiuri, S., Diligolevu, M., Quested, C., Vivili, P., \& Leeder, S. (2010). Trade and food policy: Case studies from three Pacific Island countries. Food Policy, 35(6), 556-564.

Turner, C., Aggarwal, A., Walls, H., Herforth, A., Drewnowski, A., Coates, J., Kalamatianou, S., \& Kadiyala, S. (2018). Concepts and critical perspectives for food environment research: A global framework with implications for action in low-and middle-income countries. Global Food Security, 18, 93-101.

Urata, S. (2018). The trans-pacific partnership: Origin, evolution, special features and economic implications. Journal of Southeast Asian Economies, 35(1), 22-38.

Weible, C. M., \& Sabatier, P. A. (2007). A guide to the advocacy coalition framework. in Handbook of public policy analysis: theory, politics, and methods, (pp. 123-136).

Wells-Dang, A. (2014). The political influence of civil society in Vietnam. Politics in contemporary Vietnam (pp. 162-183). Palgrave-Macmillan.

Werner, M., Contreras, P. I., Mui, Y., \& Stokes-Ramos, H. (2019). International trade and the neoliberal diet in Central America and the Dominican Republic: Bringing social inequality to the center of analysis. Social Science \& Medicine, 239, 112516.

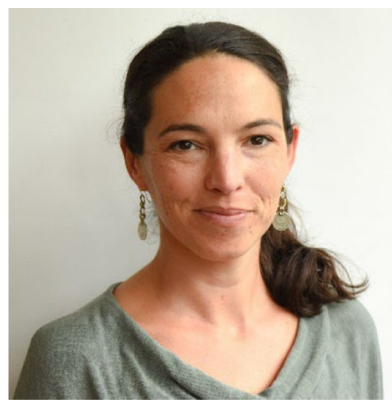

Dr Jody Harris is a Research Fellow at the Institute of Development Studies (IDS) in the UK and at the World Vegetable Center in Thailand. Her research interest is in the politics and ethics of food systems and nutrition policy. She conducts research into power in societies, including work on equity and marginalization; power in politics, including political science work on policy processes; and power in food systems, including work on trade policy and the private sector; as well as the ethics of intervention into these spaces, and ethical drivers of different actors within these systems.

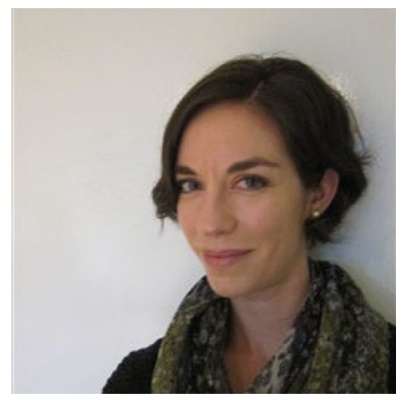

Tabitha Hrynick is a Research Officer at the Institute of Development Studies where she currently works for the Social Science in Humanitarian Action Platform. She has worked on a range of areas across the health and development space, from infectious disease, epidemics and AMR, to nutrition policy and action. She is particularly interested in how politics and power from the global to local levels shape equity in health.

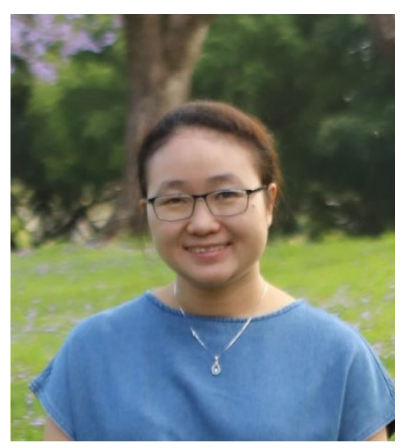

Mai Thi My Thien is currently a PhD Candidate at the Queensland University of Technology to develop and validate the nutritional assessment tools to explore the contributing factors to childhood overweight and obesity in urban Vietnam. She previously has worked as a public health officer at Ho Chi Minh City Nutrition Center, Vietnam. Her research interests are nutritional epidemiology, childhood obesity, validated dietary assessment tools, nutrition education, food policy, food and nutrition literacy, food insecurity.

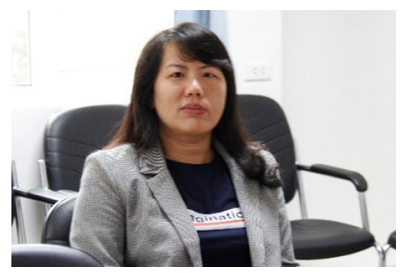

Tuyen Thi Thanh Huynh is a senior research associate working on Food Environment and Consumer Behavior lever at International Center for Tropical Agriculture and works as a Country Coordinator of CGIAR Research Program on Agriculture for Nutrition and Health (A4NH) based in Vietnam, where she leads activities of the cross-center A4NH program in its support of the national government and international agencies and movements in building sustainable food systems by ensuring the production, delivery and use of healthy food that ultimately provides economic, social and nutritional benefits to all consumers. Her research interests are nutrition sensitive food systems and food safety.

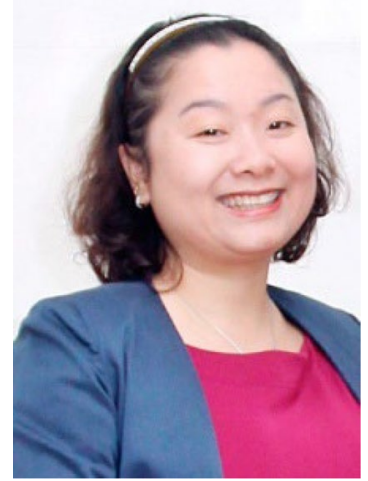

Dr Phuong Huynh is the Deputy Director of Food and Nutrition Training Centre at the National Institute of Nutrition (NIN) Vietnam since 2013. She is a medical doctor and has MSc degree in reproductive and sexual health research and $\mathrm{PhD}$ in Nutrition. She is a nutrition researcher and a lecturer at Hanoi Medical University in the field of Infant and Young Child Feeding and behaviour change communication. She has led many intervention projects with a multi-sectoral approach for improved nutrition. She has also 
led the development of a number of technical guidelines in Vietnam. She is the secretary of Scaling Up Nutrition Movement in Vietnam and a focal person for many international cooperation programs (UNICEF, A\&T, Save the Children, FHI360).

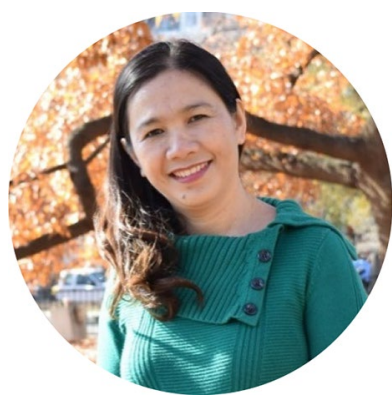

Dr Phuong Hong Nguyen is a Research Fellow in the Poverty, Health, and Nutrition Division at the International Food Policy Research Institute (IFPRI). Her research interests are in the areas of maternal and child health and nutrition. She has substantial experience in impact and process evaluation, as well as implementation and policy research in several countries including Bangladesh, Ethiopia, India and Vietnam.

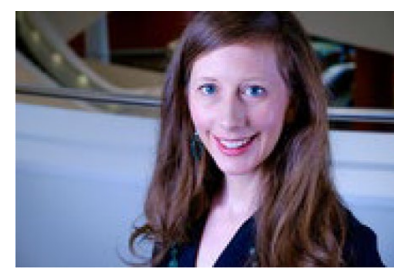

Dr Anne-Marie Thow is Associate Professor of Public Policy and Health at the Menzies Centre for Health Policy, School of Public Health, Australia. Her research uses theories of public policy making to explore facilitators and barriers to best practice public health nutrition policy, with a particular focus on the interface between economic policy and nutrition. Anne Marie currently collaborates on research in Asia, Africa and the Pacific, designed to strengthen nutrition policy making. 